Анареенко Е. Ю. ${ }^{1}$, Явелов И. С. ${ }^{1}$, Аукьянов М. М. ${ }^{1}$, Вернохаева А. Н. ${ }^{1}$, Арапкина О. М. ${ }^{1}$, Бойцов С. А. ${ }^{2}$ ${ }^{1}$ ФГБУ «Национальный медицинский исслеАовательский центр профилактической меАицины» МинзАрава России, Москва, Россия

${ }^{2}$ ФГБУ «Национальный медицинский исследовательский центр кардиологии» МинзАрава России, Москва, Россия

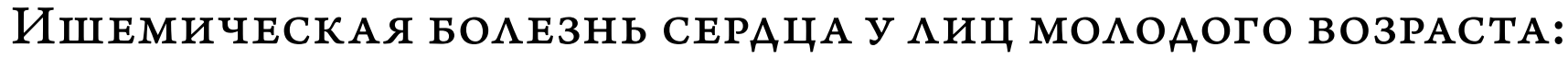 РАСПРОСТРАНЕННОСТЬ И СЕРАЕЧНО-СОСУАИСТЫЕ ФАКТОРЫ РИСКА
}

Ключевые слова: ишемическая болезнь серАца, прежАевременная ишемическая болезнь серАца, инфаркт миокарАа, эпидемиология, факторы риска.

Ссылка для цитирования: Андреенко Е. Ю., Явелов И. С., Ауквянов М.М., Вернохаева А.Н., Арапкина О.М., Бойцов С.А. Ииемическал болезнь сердиа улицмолодого возраста: распространенность и сердечно-сосудистые факторы риска. Кардиология. 2018;58(10):53-58.

РЕЗЮме

ПрежАевременной считают ишемическую болезнь серАца (ИБС), возникшую в возрасте Ао 55 мет у мужчин и Ао 65 мет у женщин. ОАнако в различных исследованиях возрастная граница Аля констатации раннего возникновения ИБС варьирует от 35 мет ао 65 мет. Смертность от ИБС среАи населения трудоспособного возраста в Российской ФеАерации в несколько раз выше, чем в США и странах Западной Европы. Больные с ранним развитием ИБС отличаются от пожилых по структуре факторов риска, клиническим проявлениям и прогнозу. У больных с ранним дебютом ИБС чаще выявляются курение, ожирение и отягощенная наслеАственность, реже - сахарный диабет и артериацьная гипертония.

Andreenko E. Yu. ${ }^{1}$, Yavelov I. S. ${ }^{1}$, Loukianov M. M. ${ }^{1}$, Vernohaeva A. N. ${ }^{1}$, Drapkina O. M. ${ }^{1}$, Boytsov S.A. ${ }^{2}$ ${ }^{1}$ National Medical Research Center for Preventive Medicine, Moscow, Russia

${ }^{2}$ National Medical Research Center for Cardiology, Moscow, Russia

\section{Ischemic Heart Disease in Subjects of Young Age: Current State of the Problem: Prevalence and Cardio-Vascular Risk Factors}

Keywords: ischemic heart disease; premature coronary artery disease; myocardial infarction; epidemiology; risk factors; genetic risk factors; pathogenesis; clinical coursee; prognosis.

For citation: Andreenko E. Yu., Yavelov I. S., Loukianov M. M., Vernohaeva A. N., Drapkina O. M., Boytsov S. A. Ischemic Heart Disease in Subjects of Young Age: Current State of the Problem: Prevalence and Cardio-Vascular Risk Factors. Kardiologiia. 2018;58(10):53-58.

SUMMARY

Ischemic heart disease (IHD) occurring at age less than 55 in men and less than 65 years in women is designated as premature IHD. However, in different studies these age limits vary from 35 years to 65 years. Among the population of working age in the Russian Federation mortality from IHD is several times higher than in the US and Europe. Patients with premature IHD differ from the elderly in structure of risk factors, clinical manifestations and prognosis. Smoking, obesity and family history of premature IHD are more common in young patients with IHD while diabetes and hypertension are less common.

$\prod^{2}$ реждевременной (premature) считают ишемическую болезнь сердца (ИБС), возникшую в возрасте Ао 55 мет у мужчин и Ао 65 мет у женщин $[1,2]$. ОАнако в различных исследованиях используется и Аругая терминология (ИБС в молодом возрасте, ИБС в очень молоАом возрасте, преждевременное развитие ИБС), а возрастной предел изучаемых больных варьирует от 35 до 65 мет, что затрудняет сопоставление полученных результатов [3-9].

В послеАние Аесятилетия частота развития ИБС у миц молодого возраста увеличивается, что преАставляет собой важную социально-экономическую проблему из-за ран- ней утраты трудоспособности и ранней смертности. Бомьные, у которых ИБС манифестировала в молодом возрасте, отличаются от пожилых по структуре факторов риска (ФР), клиническим проявлениям и прогнозу заболевания. В последнее время помимо традиционных ФР развития сердечно-сосудистых заболеваний (СС3) рассматриваются более широкий спектр признаков, ассоциированных с ранним развитием ИБС. Цель Аанного обзора - проанализировать изменяющиеся эпидемиологические тенденции, роль традиционных и Аополнительных ФР, особенности патогенеза, клинического течения и прогноза у больных с ИБС в молодом возрасте. 
ИБС у Аиц молодого возраста:

\section{распространенность}

Хотя в последние Аесятилетия в экономически развитых странах отмечается неукмонное снижение смертности от болезней системы кровообращения, по данным Всемирной организации зАравоохранения (ВО3), ИБС продолжает оставаться ведущей причиной заболеваемости и смертности как в экономически развитых, так и в развивающихся странах, и обусловливает $1 / 3$ всех смертей у миц старше 35 мет [10, 11]. В 2016 г. в Европе ИБС в структуре общей смертности у миц моложе 65 мет составила 14\% (у мужчин 16\%, у женщин 10\%) [11]. По Аанным ВОЗ, бремя болезни, связанное с ИБС, выросло с 154 млн мет жизни, утраченных из-за преждевременной смерти и нетрудоспособности, в 2010 г. Ао примерно 192 мАн в 2015 г. При этом в 2010 г. ИБС по Аанному показателю была на третьем месте после респираторных и желудочно-кишечных инфекций, а в 2015 г. заняла мидирующую позицию [12].

Хотя в Российской ФеАерации, начиная с 2004 г., отмечается тенденция к снижению смертности от болезней системы кровообращения, этот показатель остается в несколько раз выше, чем в экономически развитых странах [13]. При анамизе структуры смертности в трудоспособном возрасте в Российской Федерации за 2016г. получены данные, сопоставимые с европейскими: ИБС в структуре общей смертности трудоспособного населения составила $13,6 \%$ (у мужчин $15,4 \%$, у женщин 6,8\%) [14].

В США коэффициент смертности от ИБС в 2014г. составил 98,8 на 100000 населения, что на $35,5 \%$ ниже, чем в 2004 г. [15]. ОАнако среАи мужчин и женщин моложе 55 мет смертность от ИБС за периоА с 2000 по 2011 г. практически не изменилась (коэффициенты смертности 39,1 у мужчин и 12,3 у женщин) [5]. В Российской Федерации смертность от ИБС в 3,5 раза выше, чем в США (342,3 на 100000 населения, по Аанным за 2014 г.) [11, 13]. Коэффициенты смертности от ИБС среди населения трудоспособного возраста в Российской Федерации также в несколько раз выше, чем в странах Западной Европы: по данным за 2014г., они составмяли у мужчин и женщин 137 и 18,5 соответственно, в то время как в Великобритании среди населения моложе 65 мет 27,2 у мужчин и 7,0 у женщин, во Франции - 12,9 и 2,3 соответственно [11, 14].

Среди умерших от болезней системы кровообращения в Российской Федерации, по Аанным за 2016 г., трудоспособное население состав яет $30 \%$, при этом в структуре смертности Аоля умерших от инфаркта миокарАа (ИМ) составила 8,4\%, от Аругих форм ИБС - 37,3\% [14].

Заболеваемость ИМ в Российской Федерации с 2012 по 2016 г. оставалась практически неизменной как среди все-

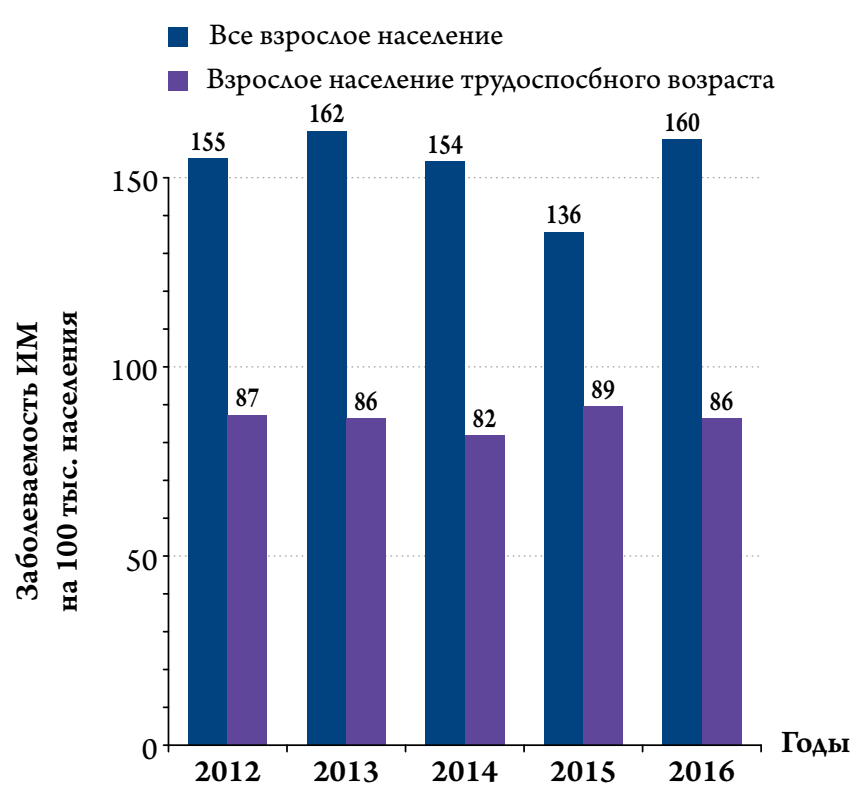

Рис. 1. Заболеваемость ИМ на 100000 человек населения Российской ФеАерации [16].

3Аесь и на рис. 2: ИМ - инфаркт миокарда.

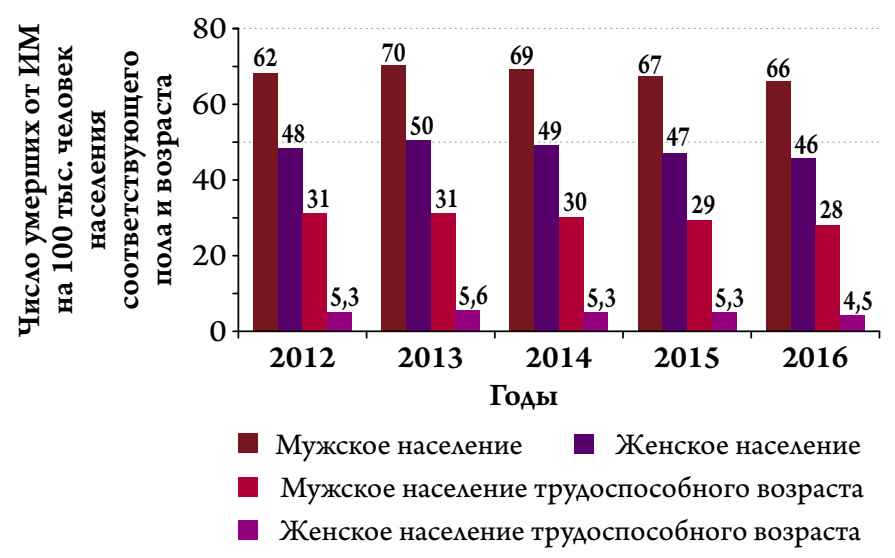

Рис. 2. Коэффициенты смертности взрослого населения Российской ФеАерации от инфаркта миокарАа [17].

го взрослого населения, так и среАи миц трудоспособного возраста (мужчины в возрасте 16-59 мет, женщины в возрасте 16-54 года) [16] (рис. 1).

Анализ смертности от ИМ с 2012 по 2016г. показал, что она остается высокой и значительно преобладает у мужчин, особенно трудоспособного возраста: смертность от ИМ у мужчин превышала смертность у женщин в общей группе в 1,4-1,5 раза, в трудоспособном возрасте - в 5,5-6,2 раза [17] (рис. 2).

\section{ИБС УАИЦ МолоАоГо возраста: ФР}

Среди ФР раннего развития ИБС выделяют традиционные и дополнительные.

Традииионные ФР развития ИБС: мужской пол; курение; артериальная гипертония (АГ); сахарный диабет 
(СА); Аислипидемия; ожирение; отягощенная наслеАственность.

Аополнительные ФР развития ИБС: генетические факторы риска; повышенный уровень мипопротеина(a) в крови; повышенный уровень фибриногена в крови; повышенный уровень D-димера в крови; фактор V Иейден; гипергомоцистеинемия; антифосфолипидный синдром; системная красная волчанка; ревматоидный артрит; болезнь Кавасаки в детском возрасте; прием пероральных контрацептивов; употребление кокаина; змоупотребление алкоголем; гипотиреоз; открытое овальное окно; ВИЧ-инфекция на высокоактивной антиретровирусной терапии; заболевания пародонта; психосоциальные факторы.

\section{Традищионные ФР развития ССЗ}

От 85 Ао 90\% больных ИБС в молодом возрасте имеют как минимум один традиционный ФР развития СС3 [18, 19], оАнако их структура отличается от таковой у больных старших возрастных групп [20].

Наиболее распространенный $Ф$ Р, связанный с ранним развитием ИБС, - курение. Число курящих среди больных ИБС моложе 45 мет составляет от 60 Ао 90\%, у пациентов старше 45 мет - от 24 Ао 56\% [7, 21, 22]. В мета-анализе, включавшем 14 международных рандомизированных исследований ИБС, у 76716 больных ИМ с подъемом сегмента ST, 35527 больных нестабильной стенокардией/ИМ без подъема сегмента ST и 10215 больных, поАвергшихся чрескожным коронарным вмешательствам, проведен анализ распространенности 4 ФР (курение, СА, АГ, гиперлипидемия) в зависимости от пола и возраста. У большинства молодых пациентов выявлен как минимум 1 ФР, самым частым из которых было курение с частотой $72 \%$ у миц моложе 45 мет, как у мужчин, так и у женщин. По сравнению с больными старшего возраста в группе пациентов моложе 45 мет реже встречались СА и $\mathrm{A} Г$, и не было различий по частоте выявления гиперлипидемии [18]. По данным регистра, в котором наблюдались 892 пациента с острым ИМ с подъемом сегмента ST и подвергшихся первичному чрескожному коронарному вмешательству, в возрасте от 18 Ао 34 мет курили $78 \%$ больных, в изученной группе в целом - $23 \%$ и процент курящих снижался по мере увеличения возраста, в котором развился ИМ [23].

Ава Аругих ФР развития ССЗ - СА и АГ по-видимому, у молодых пациентов с ИБС менее распространены, чем у пациентов старшего возраста [7, $18,21]$. Вместе с тем у молодых пациентов часто выявАяют нарушение толерантности к глюкозе. Так, в проспективном исследовании с участием 108 пациентов без СА, перенесших ИМ в возрасте моложе 45 мет, у $65 \%$ выявмены нарушение толерантности к глюкозе и гиперинсулинемия [24]. Это согласуется с Аанными Аругих исследований, в которых отмечено, что нарушение толерантности к глюкозе в отсутствие СА является ФР развития ИБС.

Частота выявления гиперхолестеринемии у молодых пациентов с ИБС сходна с таковой у пожилых пациентов, однако среди молодых больных ИБС отмечались более низкие средние уровни мипопротеинов высокой пмотности и более высокие уровни триглицеридов [25]. По данным упомянутого исследования с участием пациентов без СА, перенесших ИМ в возрасте моложе 45 мет, гипертриглицеридемия была наиболее распространенным нарушением мипидного обмена [24]. Это может быть связано с нарушением толерантности к глюкозе и преобладанием атерогенных мелких плотных частиц липопротеинов низкой плотности, увеличение числа и сниженный размер которых преАрасполагают к развитию атероскиероза [26].

Ожирение чаще встречается у больных с ранним развитием ИБС и явцяется независимым предиктором коронарного атеросклероза в молодом возрасте, что показано в ряде исследований. В частности это было продемонстрировано при сравнении распространенности ФР у пациентов, госпитализированных с острым ИМ в возрасте моложе и старше 50 еет, в регистре, включавшем 1199 больных [27]. Связь ожирения с наличием атеросклероза в молодом возрасте была продемонстрирована в исследовании аутопсий 3000 человек в возрасте 15-34 ^ет, умерших от некардиологических причин [28]. Оценивали наличие жировых полосок и атеросклеротических бляшек в правой и передней нисходящей коронарных артериях. Количество жировых полосок увеличивалось с увеличением индекса массы тела, но не зависело от толщины подкожной жировой кметчатки. С избыточной массой тела и ожирением были связаны также количество и протяженность атероскмеротических бляшек. Во Фрамингемском исследовании показано, что вклаА ожирения в возникновение ИБС У Аиц среАнего возраста может составлять Ао 23\% случаев у мужчин и $15 \%$ у женщин [29].

Аанные множества крупных проспективных эпидемиологических исследований свидетельствуют о статистически значимой ассоциации наследственности, отягощенной по раннему развитию ИБС у родителей или братьев и сестер. Так, во Фрамингемском исследовании поАтвержденное ССЗ, связанное с атероскиерозом, у одного из родителей, родного брата или сестры было ассоциировано с повышением риска развития СС3 в 2 раза, независимо от наличия Аругих традиционных ФР [30, 31]. Преждевременная смерть от ИБС в семье ассоциируется с повышенным риском смерти от ИБС, в том чисме преждевременной, у Аругих членов семьи [32]. ВкмаА 
наследственности в развитие ИБС продемонстрирован в ШвеАском исслеАовании, провеАенном на моно- и Аизиготных близнецах. В исслеАование вкмючены 21004 близнеца со сроком наблюдения 26 мет. Возраст смерти одного из близнецов от ИБС оценивался как ФР смерти второго близнеца от ИБС. СреАи мужчин риск смерти от ИБС в скучаях, когАа оАин из близнецов умер от ИБС в возрасте но 55 мет, был в 8,1 раза выше Аля монозиготных близнецов и в 3,8 раза выше Аля Аизиготных близнецов по сравнению с отсутствием ранней смерти оАного из близнецов. СреАи женщин относительный риск смерти от ИБС, в случае если оАин близнец умер до 65 мет, составим 15 и 2,6 Аля моно- и Аизиготных близнецов соответственно. По мере увеличения возраста смерти от ИБС оАного из близнецов относительный риск смерти Аругого близнеца снижался [33].

Среди молодых пациентов с ИБС чаще встречаются мица с отягощенной наслеАственностью: 41-64\% по сравнению с 12-43\% у больных старшего возраста $[7,21,22]$. В межАународном проспективном регистре CONFIRM из 27125 человек, которым была выполнена компьютерная томография коронарных артерий, 6308 мужчин моложе 55 мет и женщин моложе 65 мет без ранее Аиагностированной ИБС наблюАались в течение 3 мет. У молодых пациентов с отягощенной наслеАственностью выявлены более частое и тяжелое пораже- ние коронарных артерий, а также более высокий риск развития ИМ в течение 3 мет, чем у миц без отягощенной по ранней ИБС наслеАственности (относительный риск 2,6 при 95\% доверительном интервале от 1,4 Ао 4,8;

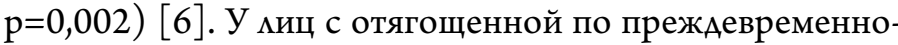
му развитию ИБС наслеАственностью ФР развития ССЗ встречаются чаще, чем у миц без отягощенной наслеАственности. К ним относятся избыточная масса тела, а также более высокие уровни хоместерина, глюкозы и инсулина в сыворотке крови [34].

\section{Закиючение}

Смертность от ишемической болезни серАца среАи населения Российской ФеАерации трудоспособного возраста в несколько раз выше, чем в США и Европе. По Аанным за 2016 г., в структуре смертности трудоспособного населения Российской ФеАерации от болезней системы кровообращения ишемическая болезнь сердца составима 45,8\%. СреАи больных трудоспособного возраста, умерших от инфаркта миокарда, преобладают мужчины. По сравнению с мицами пожилого возраста у больных с ранним дебютом ишемической болезни серАца отмечается Аругая частота факторов риска развития сердечно-сосудистых заболеваний: чаще встречаются курение, ожирение и отягощенная наслеАственность, реже - сахар ный Аиабет и артериальная гипертония.

Information about the author:

Federal State Institution National Research Center for Preventive Medicine, Moscow, Russia

Andreenko Elena Yu. - MD, PhD.

E-mail: Elena.Andreenko@gmail.com

\section{АИТЕРATУPA/REFERENCES}

1. Piepoli M. F., Hoes A. W., Agewall S. et al. 2016 European Guidelines on Cardiovascular Disease Prevention in Clinical Practice. European Heart Journal 2016;37:2315-2381. DOI:10.1093/eurheartj/ehw106

2. Developed by the committee of experts of the Russian Society of Cardiology (RSC), Russian Society of Preventive Cardiology (RSPC) RS of N-CD. Cardiovascular prevention 2017. Russ J Cardiol 2017;23 (6):7-122. DOI: dx.doi.org/10.15829/1560-40 71-2018-6-7-122. Russian (Российское кардиологическое общество. Национальное общество профикактической кардиологии. Российское общество профилактики неинфекционных забомеваний. Кардиоваскумярная профилактика 2017. Российский кардиологический журнал 2018;23 (6):7-122; http://dx.doi. org/ 10.15829/1560-4071-2018-6-7-122)

3. Carr J.J., Jacobs D. R., Terry J. G. et al. Association of coronary artery calcium in adults aged 32 to 46 years with incident coronary heart disease and death. JAMA Cardiol 2017;2 (4):391-399. DOI:10.1001/jamacardio. 2016.5493

4. Christus T., Shukkur A.M., Rashdan I. et al. Coronary Artery Disease in Patients Aged 35 or less - A Different Beast? Heart Views 2011;12 (1):7-11. DOI:10.4103/1995-705X. 81550

5. Wilmot K.A., O’Flaherty M., Capewell S. et al. Coronary heart disease mortality declines in the United States from 1979 through 2011: Evidence for stagnation in young adults, especially women. Circulation 2015;132 (11):997-1002. DOI:10.1161/ CIRCULATIONAHA. 115.015293

6. Otaki Y., Gransar H., Berman D.S. et al. Impact of family history of coronary artery disease in young individuals (from the CONFIRM registry). Am J Cardiol 2013;111 (8):1081-1086. DOI:10.1016/j.amjcard. 2012.12.042

7. Zimmerman F.H., Cameron A., Fisher L.D., Ng G. Myocardial infarction in young adults: Angiographic characterization, risk factors and prognosis (Coronary Artery Surgery Study Registry). J Am Coll Cardiol 1995;26 (3):654-661. DOI:10.1016/07351097 (95) 00254-2

8. van Loon J.E., de Maat M.P. M., Deckers J.W. et al. Prognostic markers in young patients with premature coronary heart disease. Atherosclerosis 2012;224 (1):213-217. DOI:10.1016/j.atherosclerosis. 2012.06.067

9. Jacques J., Genest M., Judith R. et al. Prevalence of risk factors in men with premature coronary artery disease. Am J Cardiol 1991;67 (15):1185-1189. https://www.ajconline.org/article/00029149 (91) 90924-A/abstract.

10. Organization WH. WHO Mortality Database. WHO. http://www. who.int/healthinfo/mortality_data/en/. Published 2015. Accessed May 25, 2016. 
11. Townsend N., Wilson L., Bhatnagar P. et al. Cardiovascular disease in Europe: Epidemiological update 2016. Eur Heart J 2016;37 (42):3232-3245. DOI:10.1093/eurheartj/ehw334

12. WHO. Global Health Estimates 2015: Deaths by Cause, Age, Sex, by Country and by Region, 2000-2015. http://www. who.int/healthinfo/global_burden_disease/estimates_country_2000_2015/en/

13. Oshchepkova E. V. Cardiovascular Disease Mortality of Population in Russian Federation in 2001-2006 and Ways of Its Lowering. Cardiologia 2009;49 (2):62-72. Russian (Ощепкова Е. В. Смертность населения от сердечно-сосудистых заболеваний в Российской Федерации в 2001-2006 гг. и пути по ее снижению. Кардиомогия 2009;49 (2):62-72.)

14. Ageeva L. I., Aleksandrova G. A., Zajchenko N.M. et al. Healthcare in Russia 2017. Federal State Statistics Service; 2017. Russian (Агеева И.И., Александрова Г.А., Зайченко Н.М. и Ар. ЗАравоохранение в России. 2017. Федеральная служба госуАарственной статистики 2017)

15. Benjamin E.J., Blaha M.J., Chiuve S.E. et al. Heart Disease and Stroke Statistics - 2017 Update: A Report from the American Heart Association. Circulation 2017;135: e1 - e458. DOI:10.1161/CIR. 0000000000000485

16. Ministry of health. Statistical materials "The incidence rate of adult population of Russia.” 2016 Russian (Статистические материалы «Заболеваемость взрослого населения России». 2016 Минзарав http://mednet.ru/ru/statistika/zabolevaemost-naseleniya. html)

17. Center for Demographic Research M (Russia). Russian Fertility and Mortality Database. 2016 Russian (Российская база Аанных по рожАаемости и смертности. Центр Аемографических исследований Российской экономической школы, Москва (Россия) 2016. http://demogr.nes.ru/index. php/ru/demogr indicat/data)

18. Khot U.N., Khot M.B., Bajzer C.T. et al. Prevalence of conventional risk factors in patients with coronary heart disease. JAMA 2003;290 (7):898-904. DOI:10.1001/jama. 290.7.898

19. Chouhan L., Hajar H. A., Pomposiello J. C. Comparison of thrombolytic therapy for acute myocardial infarction in patients aged \&lt;35 and \&gt;55 years. Am J Cardiol 1993;71 (2):157-159. DOI:10.1016/0002-9149 (93) 90731-Q

20. Celik T., Iyisoy A. Premature coronary artery disease in young patients: An uncommon but growing entity. Int J Cardiol 2010;144 (1):131-132. DOI: $10.1016 / j$. ijcard. 2008.12.150

21. Cole J.H., Miller J. I., Sperling L. S., Weintraub W. S. Long-term follow-up of coronary artery disease presenting in young adults. J Am Coll Cardiol 2003;41 (4):521-528. DOI:10.1016/S0735-1097 (02) 02862-0

22. Hoit B.D., Gilpin E.A., Henning H. et al. Myocardial infarction in young patients: An analysis by age subsets. Circulation 1986;74 (4):712-721. DOI:10.1161/01. CIR. 74.4.712
23. Larsen G.K., Seth M., Gurm H.S. The ongoing importance of smoking as a powerful risk factor for ST-segment elevation myocardial infarction in young patients. JAMA Intern Med 2013;173 (13):1261-1262. DOI:10.1001/jamainternmed. 2013.6075

24. Malmberg K., Båvenholm P., Hamsten A. Clinical and biochemical factors associated with prognosis after myocardial infarction at a young age. J Am Coll Cardiol 1994;24 (3):592-599. DOI:0735-1097 (94) 90002-7 [pii]

25. Chen L., Chester M., Kaski J. C. Clinical factors and angiographic features associated with premature coronary artery disease. Chest 1995; 108 (2):364-369. DOI:10.1378/ chest. 108.2.364

26. Carmena R. Atherogenic Lipoprotein Particles in Atherosclerosis. Circulation2004;109(23_suppl_1):III-2-III-7.DOI:10.1161/01. CIR. 0000131511.50734.44

27. Matsis K., Holley A., Al-Sinan A. et al. Differing Clinical Characteristics Between Young and Older Patients Presenting with Myocardial Infarction. Hear Lung Circ 2017;26 (6):566-571. DOI: $10.1016 /$ j. hlc. 2016.09.007

28. McGill H. C., McMahan C. A., Herderick E.E. et al. Obesity accelerates the progression of coronary atherosclerosis in young men. Circulation 2002;105 (23):2712-2718. DOI:10.1161/01. CIR. 0000018121.67607. CE

29. Turpie A.G. G., Bauer K.A., Eriksson B.I., Lassen M.R. Overweight and obesity as determinants of cardiovascular risk: The Framingham experience. Arch Intern Med 2002;162 (16): 1867-1872. DOI:10.1001/archinte. 162.16.1867

30. Lloyd-Jones D.M., Nam B.-H., D’Agostino R.B. et al. Parental cardiovascular disease as a risk factor for cardiovascular disease in middle-aged adults: a prospective study of parents and offspring. JAMA J Am Med Assoc 2004;291:2204-2211. DOI:10.1001/jama. 291.18.2204

31. Murabito J.M., Pencina M.J., Nam B.-H. et al. Sibling cardiovascular disease as a risk factor for cardiovascular disease in middleaged adults. JAMA J Am Med Assoc 2005;294 (24):3117-3123. DOI:10.1001/jama. 294.24.3117

32. Bachmann J. M., Willis B. L., Ayers C. R. et al. Association between family history and coronary heart disease death across long-term follow-up in men: The cooper center longitudinal study. Circulation 2012;125 (25):3092-3098. DOI:10.1161/CIRCULATIONAHA. 111.065490

33. Marenberg M.E., Risch N., Berkman L. F. et al. Genetic susceptibility to death from coronary heart disease in a study of twins. N Engl J Med 1994;330 (15):1041-1046. DOI:10.1056/NEJM19940414 3301503

34. Bao W., Srinivasan S. R., Wattigney W.A., Berenson G. S. The relation of parental cardiovascular disease to risk factors in children and young adults. The Bogalusa Heart Study. Circulation 1995;91 (2):365-371. DOI:10.1161/01. CIR. 91.2.365

Поступима 05.05.18 (Received 05.05.18) 